\title{
Urinary incontinence in the puerperium and its impact on the health-related quality of life ${ }^{1}$
}

\author{
Lígia da Silva Leroy² \\ Maria Helena Baena de Moraes Lopes ${ }^{3}$
}

This case-control study evaluated whether UI in the puerperium compromises the healthrelated quality of life (HRQOL) and if so, in which aspects. The study included 344 women (77 case group and 267 control group) up to 90 days postpartum, who were attended the Obstetrics Outpatient Clinic of a public teaching hospital, for the postpartum follow up consultation. A socio-demographic and clinical data questionnaire formulated and validated for the study, the International Consultation on Incontinence Questionnaire - Short-Form (ICIQ-SF), the King's Health Questionnaire (KHQ) and the Medical Outcomes Study 36 Item Short Form Health Survey (SF-36), were applied. The mean score of the ICIQ-SF was 13.9 (SD: 3.7). The case group presented high mean scores in the domains Impact of the Incontinence, Emotions, Daily Activity Limitations and Physical Limitations, of the KHQ. The groups differed significantly in the domains Physical Aspects, Pain, General Health Status, Vitality, Social Aspects and Mental Health of the SF-36. It is concluded that UI significantly affects the physical and mental health of puerperae.

Descriptors: Urinary Incontinence; Postpartum Period; Quality of Life.

\footnotetext{
${ }^{1}$ Article extracted from master's thesis "Incontinência urinária no puerpério: fatores de risco e impacto na qualidade de vida" presented to Faculdade de Ciências Médicas, Universidade Estadual de Campinas, Brazil.

2 MSc, Universidade Estadual de Campinas, Brazil.

${ }^{3}$ Free lecturer, Associate Professor, Departamento de Enfermagem, Faculdade de Ciências Médicas, Universidade Estadual de Campinas, Brazil.
}

Corresponding Author:

Lígia da Silva Leroy

Rua São Pedro, 188

Centro

CEP: 18540-000, Porto Feliz, SP, Brasil

E-mail: ligialeroy@yahoo.com.br 


\title{
A incontinência urinária no puerpério e o impacto na qualidade de vida relacionada à saúde
}

Trata-se de estudo caso-controle que avaliou se a incontinência urinária (IU) no puerpério compromete a qualidade de vida relacionada à saúde (QVRS) e em quais aspectos. Incluíram-se 344 puérperas (77 casos e 267 controles) com até 90 dias pós-parto, que compareceram ao ambulatório de obstetrícia de um hospital público e de ensino, para revisão pós-parto. Aplicou-se questionário formulado e validado para o estudo, o International Consultation on Incontinence Questionnaire - Short -Form (ICIQ-SF), o King's Health Questionnaire (KHQ) e o Medical Outcomes Study 36 - Item Short Form Health Survey (SF-36). O escore médio do ICIQ-SF foi 13,9 ( dp=3,7). Casos apresentaram pontuação média elevada nos domínios impacto da incontinência, emoções, limitações de atividades diárias e limitações físicas do KHQ. Os grupos diferiram significativamente nos domínios aspectos físicos, dor, estado geral de saúde, vitalidade, aspectos sociais e saúde mental do SF-36. Conclui-se que a IU afeta significativamente a saúde física e mental de puérperas.

Descritores: Incontinência Urinária; Período Pós-Parto; Qualidade de Vida.

\section{La incontinencia urinaria en periodo de posparto y su impacto en la calidad de vida relacionada a salud}

\begin{abstract}
Estudio caso-controle ha evaluado se la incontinencia urinaria posparto afecta la calidad de vida relacionada a salud y en que aspectos. Serán incluidas 344 mujeres (77 casos y 267 controles) hasta 90 días posparto que asistieron a la Clínica de Obstetricia de un hospital de público y de enseñanza. Fue aplicado cuestionario formulado y validado, el "International Consultation on Incontinence Questionnaire - Short -Form" (ICIQ-SF), "King's Health Questionnaire" (KHQ) y "Medical Outcomes Study 36 - Item Short Form Health Survey" (SF-36). La media del ICIQ-SF fue 13,9 (DP: 3,7). Casos tenían altos puntajes en los dominios del Impacto de la Incontinencia, Emociones, Limitaciones de las Actividades Diarias y Limitaciones Físicas del KHQ. Los grupos presentaron diferencias significativamente en los dominios Aspectos Físicos, Dolor, Estado General de la Salud, Vitalidad, Aspectos Sociales y Salud Mental del SF-36. Se concluyó que la incontinencia urinaria afecta de manera significativa la salud física y mental de las madres.
\end{abstract}

Descriptores: Incontinencia Urinaria; Periodo de Posparto; Calidad de Vida.

\section{Introduction}

Urinary incontinence (UI) in the puerperium has been reported as a hygiene problem ${ }^{(1-2)}$, which interferes with work, with the social and sexual lives of the women ${ }^{(1)}$, and can have a negative impact on the health related quality of life (HRQOL) (3). Urinary incontinence, defined as "the complaint of any involuntary loss of urine"(4), can affect people of all ages ${ }^{(5)}$. During pregnancy, the prevalence of UI ranges from $36 \%^{(6)}$ to $58 \%{ }^{(7)}$ and in the puerperium rates are described from $27 \%{ }^{(8)}$ to $33 \%{ }^{(9)}$, depending on the time frame and methodology of the studies ${ }^{(9-10)}$. The most common type of UI in the postpartum period is stress
UI (SUI) ${ }^{(1,8-14)}$, followed by mixed UI (MUI) $)^{(1,8,12)}$ and urge UI (UUI) ${ }^{(1,8,12)}$. In general, urinary loss is infrequent ${ }^{(9-10,14)}$ and in small quantities ${ }^{(10,13-14)}$. The impact of the UI varies according to age, type of UI, differences in coping skills and quality of social support ${ }^{(5)}$. Incontinent individuals may present anxiety, depression, isolation and social exclusion ${ }^{(5)}$. Urinary incontinence may cause suffering and incontinent women face difficulties in dealing with this complaint ${ }^{(15)}$.

The puerperium is a period in which diverse physical and psychological modifications occur. To 
investigate the quality of life postpartum, the use of a generic health questionnaire in parallel to one specific for the determined condition has been recommended, in order to exclude the effect of morbidities often present, such as perineal pain and postpartum depression(6). According to the World Health Organization (WHO), the quality of life is a broad, multifaceted concept, which incorporates physical, psychological and social aspects and involves the perception of the individual regarding their condition, in the cultural context in which they live ${ }^{(16)}$. The HRQoL refers to the impact of an illness or injury on the different aspects of life ${ }^{(17)}$.

The investigation of the HRQOL of incontinent puerperae is of fundamental importance to verify the compromise that UI may generate in the diverse areas of life and to propose measures that can minimize this and contribute to improving the health and well-being of this population. The nurse must know the aspects of the HRQoL affected by postpartum UI, in order to provide targeted care to this population, implementing preventive strategies during the prenatal and postpartum periods. Faced with this, the aim of this study was to evaluate whether postpartum UI compromised the HRQoL of women attending a public tertiary teaching hospital of the state of São Paulo, Brazil, and, if so, in what aspects.

\section{Method}

This is a case-control study conducted between May and December 2010, with women in the 90 days postpartum period, who attended the Obstetrics Outpatient Clinic of a public tertiary teaching hospital in the state of São Paulo, Brazil, for the postpartum follow up consultation. Women with urinary incontinence before pregnancy and those who had any of the following conditions were excluded from the study: twin pregnancy, the presence of: hypertension, diabetes mellitus, chronic obstructive pulmonary disease, neurological disease, urinary tract infection, renal calculus, previous history of pelvic surgery (excluding cesarean section), current treatment for UI and/or the use of medication that interferes with the function of the lower urinary tract.

The sample size was calculated to detect an odds ratio of 3.0 at a ratio of one case to three controls, assuming a significance level of $5 \%$ and a power of $80 \%$, with the prevalence of exposure among the case group estimated at $20 \%{ }^{(1)}$. The sample size calculation was estimated to be 74 cases and 222 controls. The case group (incontinent puerperae) and control group (continent puerperae) were identified by means of questions 3 and 4 of the International Consultation on Incontinence Questionnaire - Short Form (ICIQ-SF), validated in Portuguese ${ }^{(18)}$, which evaluates, respectively, frequency and quantity of urinary loss, making it possible to identify whether the person presents UI or not. The woman was included in the case group if she reported any frequency and/or quantity of urinary loss during the past four weeks, and the control group if she reported no complaint of urinary loss, considering the immediate postpartum period until the time of inclusion in the study.

For the socio-demographic and clinical data collection a questionnaire was prepared, which was submitted to content validity analysis, performed by three judges with experience in the areas of obstetrics and gynecology/or urogynecology. Some alterations in the questions and formatting were suggested, resulting in the final instrument. This was pre-tested with ten puerperae, which showed that no further modifications were necessary.

The instruments used for the evaluation of the HRQOL were the ICIQ-SF(18), the $\mathrm{KHQ}^{(19)}$, and the SF36(20), previously validated in Brazil. The ICIQ-SF is a self-administered questionnaire consisting of four questions, which qualify the urinary loss and evaluate the impact of UI on the quality of life through a scale, ranging from 0 (does not interfere) to 10 (interferes a lot), which aims to measure how much the loss of urine interferes in the daily life. The score is given by the sum of questions 3, 4 and 5, ranging from 0 to 21, and the higher the score, the greater the severity of urinary loss and impact on the quality of life ${ }^{(18)}$. In the present study, the Cronbach's alpha coefficient of this scale was 0.69.

The KHQ is a questionnaire that evaluates the perceived symptoms and the impact of the UI on different domains of quality of life. It consists of 21 questions divided into eight domains (General Health Perception, Incontinence Impact, Daily Activity Limitations, Physical Limitations, Social Limitations, Personal Relationships, Emotions, and Sleep and Energy) and two scales (Urinary Symptoms and Severity Measures). Scores range from 0 to 100 in each domain and the higher the score, the worse the quality of life related to that domain ${ }^{(19)}$. In the present study, the Cronbach's alpha coefficient of the total scale was 0.90 , varying from 0.87 to 0.91 .

The SF-36 is a generic instrument for evaluating the HRQoL, composed of a multidimensional questionnaire with 36 items encompassed in eight scales (Functional capacity, Physical Aspects, Pain, General Health Status, 
Vitality, Social Aspects, Emotional Aspects, and Mental Health). The possible score is from 0 to 100 in each domain and the higher the score, the better the evaluated health status(20). In the present study the Cronbach's alpha coefficient for the total scale was 0.81 , ranging from 0.77 to 0.81 in the eight domains.

Regarding the sociodemographic characteristics of the sample, the following variables were considered: age, race, marital status, schooling and income. The clinical data related to the pregnancy and birth were obtained from the medical records of the puerperal or the newborn.

The study was approved by the Research Ethics Committee of the institution (protocol No. 247/2010), following the current legislation in the country. The women who met the selection criteria were invited to participate in the study and, after they signed the Terms of Free Prior Informed Consent, the data collection was initiated. The questionnaires were completed in a selfapplicable manner by the respondents, however, they could seek clarification from the researcher when ever necessary. All the puerperae responded to the ICIQ-SF first. The case group responded to the sociodemographic and clinical data questionnaire, the $\mathrm{KHQ}$ and the SF-36, while the control group responded to the sociodemographic and clinical data questionnaire and the SF-36. The order of response to the questionnaires was nonconsecutive.

Descriptive analysis was used, calculating the absolute and relative frequencies of the categorical variables and measures of position and dispersion of the continuous variables. To evaluate the adherence of the continuous variables to the normal distribution, the Kolmogorov-Sminov test was applied. The groups were compared according to their sociodemographic and clinical characteristics, using Pearson's chi-square or Fisher's exact test for the categorical variables and the Mann-Whitney or Kruskal-Wallis test for the continuous variables. As the domains did not present normal distributed, the Mann-Whitney test was used to compare the SF-36 scores between the case and control groups. The value of $p<0.05$ ( $\alpha=5 \%$ ) was adopted as the critical level for all tests and the SAS software (version 9.1.3, SAS Institute Inc., Cary, NC, USA, 2002-2003) was used for the data analysis.

\section{Results}

In the data collection period 441 women were approached. Of these, 97 were excluded due to not meeting the inclusion criteria. Included and excluded puerperae differed significantly (according to the MannWhitney test) regarding age $(p<0.0001)$ and schooling $(p=0.0496)$, with higher measurements among those excluded, and were similar regarding the length of puerperium $(p=0.9870)$. A total of 344 women were, consequently, included, with a mean age of 25.9 years $(\mathrm{SD}=7.7$, ranging from 13 to 45 years) and mean puerperium period of 52.3 days $(S D=12.0$, ranging from 12 to 87 days). The majority were non-white (65.7\%), considered mixed race and black (there were no subjects in the categories Asian or indigenous), married (70.9\%), had a mean of 9.9 years of schooling $(S D=2.7$, ranging from 05 to 18 years) and a mean monthly household income of approximately two minimum wages or $R \$ 1,212.50$ ( $S D=773.5$, ranging from $R \$ 200.00$ to $\mathrm{R} \$ 6,000.00)$.

Regarding the parity, 53.8\% (185) were primiparae and $46.2 \%$ (159) were multiparae. The majority of the puerperae underwent cesarean sections (54.9\% or 189$), 39.5 \%$ (136) delivered vaginally and $5.5 \%$ (19) underwent forceps deliveries. In relation to the previous births, $12.2 \%$ (42) had only cesarean delivery, $15.1 \%$ (52) only vaginal delivery (normal or forceps) and $18.9 \%$ (65) both. Episiotomy was performed in $23.8 \%$ (82) of the women and $17.2 \%$ (59) of them had some degree of perineal laceration. The women were around the $38^{\text {th }}$ week of gestation at the time of the birth ( $S D=3.1$, ranging from 24 to 42 ) and had a mean of 02 living children ( $S D=1.0$, ranging from 01 to 07 ). During the pregnancy UI was reported by $28.2 \%$ (97) of the puerperae.

The case and control groups differed significantly according to the chi-square test, with UI during pregnancy significantly more frequent $(p<0.0001)$ in the case group $(70.1 \%)$ compared to the control group $(16.1 \%)$; birth, with a significantly higher frequency $(p=0.0291)$ of multiparae within the case group (57.1\%) compared to the control group (43.1\%); and, according to the Mann-Whitney test, gestational age at birth, with means significantly higher $(p=0.0365)$ in the case group $(38.4, \mathrm{SD}=2.6)$ than the control group (37.6, SD=3.2). The other sociodemographic and clinical variables mentioned above were similar between the groups.

The data in Table 1 show the urinary incontinence characteristics in the puerperium. The mean of interference in the daily life, evaluated using a scale from 0 (does not interfere) to 10 (interferes a lot) of the ICIQ-SF was 8.1 ( $S D=2.2$, ranging from 02 to 10 ) with $42.9 \%$ (33) of the women attributing the maximum score. The mean 
total score of the ICIQ-SF was 13.9 ( $S D=3.7$, ranging the puerperium, though generally of small quantity, is from 06 to 20), which identified that the urinary loss in frequent, with a high impact on daily life.

Table 1 - Characteristics of urinary incontinence in the puerperium $(n=77)$, Campinas, SP, Brazil, 2010

\begin{tabular}{|c|c|c|c|}
\hline \multirow{2}{*}{ Characteristic } & \multirow{2}{*}{ Category } & \multicolumn{2}{|c|}{ Incontinent puerperae (case group) } \\
\hline & & $\mathbf{n}$ & $\%$ \\
\hline \multirow[t]{3}{*}{ Ul type } & Stress UI & 35 & 45.5 \\
\hline & Urge UI & 20 & 26.0 \\
\hline & Mixed UI & 22 & 28.6 \\
\hline \multirow[t]{4}{*}{ Frequency of episodes of urinary incontinence } & Once/week or less & 09 & 11.7 \\
\hline & Twice or three times/week & 20 & 26.0 \\
\hline & Once/day & 14 & 18.2 \\
\hline & Several times per day & 34 & 44.2 \\
\hline \multirow[t]{3}{*}{ Perception of the quantity of urine lost } & Low & 55 & 71.4 \\
\hline & Moderate & 13 & 16.9 \\
\hline & High & 09 & 11.7 \\
\hline \multirow[t]{3}{*}{ Interference in the daily life* } & 2 to 3 & 05 & 6.5 \\
\hline & 4 to 7 & 18 & 23.4 \\
\hline & 8 to 10 & 54 & 70.1 \\
\hline \multirow[t]{5}{*}{ Situations of urinary incontinence ${ }^{\dagger}$} & When coughing or sneezing & 44 & 57.1 \\
\hline & When doing physical activities & 38 & 49.4 \\
\hline & Before getting to the bathroom & 20 & 26.0 \\
\hline & When sleeping & 03 & 3.9 \\
\hline & When dressing after urinating & 02 & 2.6 \\
\hline
\end{tabular}

*Measured by means of an analog scale (ranging from 0 to 10 )

${ }^{+}$The respondent could indicate one or more situations of urinary loss, therefore, the total does not equal $100 \%$.

The data in Table 2 show the scores achieved in the domains of the KHQ. A high mean score was verified in the Incontinence Impact $(73.6, \mathrm{SD}=26.7)$, Emotions
(71.4, SD=29.9), Daily Activity Limitations (59.1 $\mathrm{SD}=32.3)$ and Physical Limitations (59.1, $\mathrm{SD}=32.6)$ domains.

Table 2 - Scores of the KHQ domains in incontinent puerperae $(n=77)$, Campinas, SP, Brazil, 2010

\begin{tabular}{|c|c|c|c|c|c|}
\hline Domains & Mean & SD & Median & Q1 - Q3 & Minimum-Maximum \\
\hline General health perception & 31.2 & 22.6 & 25.0 & $25-25$ & $0-100$ \\
\hline Incontinence impact & 73.6 & 26.7 & 66.7 & $66.7-100$ & $33.3-100$ \\
\hline Daily activity limitations & 59.1 & 32.3 & 66.7 & $33.3-83.3$ & $0-100$ \\
\hline Physical limitations & 59.1 & 32.6 & 66.7 & $33.3-83.3$ & $0-100$ \\
\hline Social limitations & 54.0 & 30.7 & 55.6 & $33.3-77.8$ & $0-100$ \\
\hline Personal relationships & 31.8 & 27.7 & 33.3 & $0-33.3$ & $0-100$ \\
\hline Emotions & 71.4 & 29.9 & 77.8 & $44.4-100$ & $0-100$ \\
\hline Sleep and energy & 46.5 & 23.6 & 50.0 & $33.3-66.7$ & $0-100$ \\
\hline Severity measures & 55.2 & 21.5 & 60.0 & $46.7-66.7$ & $0-100$ \\
\hline
\end{tabular}


The data in Table 3 presents the mean scores achieved in the ICIQ-SF and KHQ domains according to the type of UI. It was observed that women with MUI had significantly higher mean scores in the ICIQ-
SF and in the majority of the KHQ domains, except in the Incontinence Impact $(p=0.0717)$, Personal Relationships $(p=0.1767)$ and Sleep and Energy $(p=0.3740)$ domains.

Table 3 - Scores of the ICIQ-SF and KHQ domains, according to the type of UI ( $n=77)$ - Campinas, SP, Brazil, 2010

\begin{tabular}{|c|c|c|c|c|}
\hline \multirow{2}{*}{ Questionnaire } & \multicolumn{3}{|c|}{ Ul type } & \multirow{2}{*}{$p$ value * } \\
\hline & Stress UI & Urge UI & Mixed UI & \\
\hline ICIQ-SF & $13.6(3.1)$ & $12.6(3.8)$ & $15.6(4.1)$ & 0.0313 \\
\hline \multicolumn{5}{|l|}{ KHQ - Domains } \\
\hline General health perception & $25.0(18.2)$ & $27.5(19.7)$ & $44.3(26.7)$ & 0.0067 \\
\hline Incontinence impact & $72.4(26.2)$ & $65.0(27.5)$ & $83.3(24.7)$ & 0.0717 \\
\hline Daily activity limitations & $55.2(28.8)$ & $48.3(31.5)$ & $75.0(33.6)$ & 0.0043 \\
\hline Physical limitations & $58.6(30.1)$ & $38.3(27.6)$ & $78.8(29.6)$ & $<0.0001$ \\
\hline Social limitations & $49.8(26.6)$ & $43.3(32.6)$ & $70.2(29.8)$ & 0.0053 \\
\hline Personal relationships & $30.5(21.6)$ & $24.6(29.1)$ & $40.2(33.6)$ & 0.1767 \\
\hline Emotions & $74.6(25.9)$ & $55.6(30.6)$ & $80.8(30.7)$ & 0.0085 \\
\hline Sleep and energy & $44.8(18.4)$ & $44.2(26.6)$ & $51.5(28.1)$ & 0.3740 \\
\hline Severity measures & $56.0(18.0)$ & $46.0(22.7)$ & $62.4(23.5)$ & 0.0241 \\
\hline
\end{tabular}

Data expressed as mean (standard deviation)

* $p$ value calculated using the Kruskal-Wallis Test

The irritative urinary symptoms most commonly reported by the case group were frequency $(88.3 \%)$, nocturia (87\%) and urgency (54.5\%). According to Fisher's Exact Test, urgency was associated with MUI and UUI $(p<0.0001)$, but not SUI. The data in Table 4 describe the scores achieved in the SF-36 domains for the case and control groups. There was a significant difference in the Physical Aspects $(p=0.0047)$, Pain $(p=0.0419)$, General Health Status $(p=0.0002)$, Vitality $(p=0.0072)$, Social Aspects $(p=0.0318)$ and Mental Health $(p=0.0001)$ domains of the SF-36, with lower mean scores in the case group.

Table 4 - Comparison of the mean scores obtained by the case and control groups in the SF-36 domains, Campinas, SP, Brazil, 2010

\begin{tabular}{|c|c|c|c|c|c|c|c|c|c|c|c|}
\hline \multirow[b]{2}{*}{ Domains } & \multicolumn{5}{|c|}{ Case group $n=77$} & \multicolumn{5}{|c|}{ Control group $n=267$} & \multirow[b]{2}{*}{$p$ value } \\
\hline & Mean & SD & Median & Q1-Q3 & $\begin{array}{l}\text { Minimum- } \\
\text { Maximum }\end{array}$ & Mean & SD & Median & Q1-Q3 & $\begin{array}{l}\text { Minimum- } \\
\text { Maximum }\end{array}$ & \\
\hline Functional capacity & 82.1 & 22.6 & 95.0 & $70-100$ & $20-100$ & 86.8 & 20.1 & 100.0 & $80-100$ & $0-100$ & 0,089 \\
\hline Physical aspects & 65.9 & 43.1 & 100.0 & $0-100$ & $0-100$ & 80.0 & 36.0 & 100.0 & $50-100$ & $0-100$ & 0,0047 \\
\hline Pain & 62.7 & 26.1 & 62.0 & $41-90$ & $0-90$ & 69.6 & 24.2 & 90.0 & $41-90$ & $22-90$ & 0,0419 \\
\hline General health status & 72.7 & 21.2 & 82.0 & $60-87$ & $25-100$ & 81.9 & 16.9 & 87.0 & $82-92$ & $25-100$ & 0,0002 \\
\hline Vitality & 50.9 & 24.3 & 55.0 & $30-70$ & $5-95$ & 59.6 & 23.8 & 65.0 & $35-80$ & $10-100$ & 0,0072 \\
\hline Social aspects & 79.7 & 26.6 & 100.0 & $50-100$ & $0-100$ & 86.6 & 22.8 & 100.0 & $75-100$ & $25-100$ & 0,0318 \\
\hline Emotional aspects & 88.7 & 29.9 & 100.0 & $100-100$ & $0-100$ & 88.8 & 28.4 & 100.0 & $100-100$ & $0-100$ & 0,7957 \\
\hline Mental health & 59,0 & 21,3 & 56,0 & $44-76$ & $12-100$ & 69,3 & 19,8 & 72,0 & $56-84$ & $16-100$ & 0,0001 \\
\hline
\end{tabular}

$\mathrm{SD}=$ standard deviation, $\mathrm{Q} 1=$ first quartile, $\mathrm{Q} 3=$ third quartile. $* p$ value calculated using the Mann-Whitney test 


\section{Discussion}

In this study, SUI was the most frequent in the puerperium and the quantity of urine lost was low, which is similar to previous studies(1,8-14). The high frequency of episodes of urinary loss is emphasized, unlike other studies in which this was of low frequency after the birth ${ }^{(1,9-11,14)}$. This difference may be explained by the recent postpartum period covered (up to 90 days). With regard to situations of urinary loss, the high proportion of women that reported loss when coughing or sneezing and/or during physical activities corresponds to the higher rates of SUI and MUI found. The daily life interference was significant and the impact on the quality of life, demonstrated by the ICIQ-SF score was high. This fact differs from previous studies that evidenced little effect in the daily life ${ }^{(10,21)}$ and low impact on the quality of life(21), however, these included only primiparae and one of them(21) evaluated only SUI.

In evaluating the HRQoL of the case group using the $\mathrm{KHQ}$, higher means were observed in the domains Incontinence Impact, Emotions, Daily Activity Limitations and Physical Limitations, which indicates a high impact of the UI in these areas. The results of the present study differ from a previous study(6), in which higher scores were noted in the General Health Perception and Personal Relationships domains, however this study included only primiparae. Multiparous women may be more burdened by having other children and the presence of UI may further affect the HRQOL of these women. A study conducted in the same location as the present study(14) found higher mean scores in the domains General Health Perception, Incontinence Impact and Severity Measures, however, had a small sample size $(n=22)$.

Regarding the impact of the different types of UI on the quality of life, it was observed that puerperae with MUI had higher mean scores in the ICIQ-SF and in the majority of the KHQ domains. A previous study also showed worse HRQoL in women with MUI(22). This indicates that MUI is responsible for the greatest impact on the HRQoL and reveals the importance of implementing treatment specific for this type of UI. The most frequent urinary symptoms among the case group were in agreement with a previous study(6). The association between urinary urgency and UUI and MUI is consistent with the characteristics of these types of incontinence.

The mean scores of the SF-36 domains differed between the case group and the control group in the domains Physical Aspects, Pain, General Health Status, Vitality, Social Functioning and Mental Health, with lower scores in the case group, suggesting that the UI may be interfering in these domains. The lowest mean scores obtained by the two groups in the Vitality domain (assessed by questions that investigate how long the individual has felt vigorous, energetic, or exhausted, tired), reveals that the post-partum state and the new tasks arising from the arrival of the baby can compromise this aspect, which is compounded when the woman has UI. The Mental Health domain includes questions about how long the person has been feeling nervous, depressed, calm, unmotivated or happy. The low mean score achieved by the control group and the case group in this domain indicates the need for services that offer mental support for the women after the birth.

The short postpartum period covered (up to 90 days) limited analyzes and comparisons with studies that covered longer periods. The data of the present study may be extrapolated to puerperae with sociodemographic and clinical characteristics similar to those described. The results show that the UI significantly affected the HRQoL, when using generic and specific instruments. Due to the lack of studies, there is a need for more studies that investigate the HRQoL of incontinent puerperae using these questionnaires. To know the domains of the HRQoL affected by UI is of fundamental importance in order to better direct the actions aimed at improving the health and well-being of this population.

\section{Conclusions}

The results of the ICIQ-SF showed that, in the puerperium, urinary loss, although in low quantities, was frequent and greatly compromised the quality of life. Using the KHQ, a high impact of UI was observed in the domains Incontinence Impact, Emotions, Daily Activity Limitations and Physical Limitations. The HRQoL of the control and case groups differed in the domains Physical Aspects, Pain, General Health Status, Vitality, Social Aspects and Mental Health of the SF-36, in which these were worse for the case group, revealing greater compromise of the HRQoL in these aspects due to the UI. Urinary incontinence significantly affects aspects of the physical and mental health of puerperae, especially those with MUI. 


\section{References}

1. Glazener CMA, Herbison GP, MacArthur C, Lancashire R, McGee MA, Grant AM, et al. New postnatal urinary incontinence: obstetric and other risk factors in primiparae. BJOG. 2006;113:208-17.

2. Herrmann V, Scarpa K, Palma PCR, Riccetto CZ. Stress urinary incontinence 3 years after pregnancy: correlation to mode of delivery and parity. Int Urogynecol J. $2009 ; 20: 281-8$.

3. Handa VL, Zyczynski HM, Burgio KL, Fitzgerald MP, Borello-France D, Janz NK, et al. The impact of fecal and urinary incontinence on quality of life 6 months after childbirth. Am J Obstet Gynecol. 2007;197:636.e1-6.

4. Abrams P, Cardoso L, Fall M, Griffiths D, Rosier P, Ulmesten $U$, et al. The standardization of terminology of lower urinary tract function: report from the standardization sub-committee of the international continence society. Urology. 2003;61:37-49.

5. National Institute of Health (NIH). State-of-theScience Conference Statement on Prevention of Fecal and Urinary Incontinence in Adults. [Internet]. 2007; [acesso 2 jun 2010]. 24(1). Disponível em: http:// consensus.nih.gov/incontinence.htm.

6. Dolan LM, Walsh D, Hamilton S, Marshall K, Thompson $\mathrm{K}$, Ashe RG. A study of quality of life in primigravidae with urinary incontinence. Int Urogynecol J. 2004;15:160-4.

7. Wesnes SL, Rortveit G, Bo K, Hunskaar S. Urinary incontinence during pregnancy. Obstet Gynecol. 2007;109(4):922-8.

8. Serati M, Salvatore S, Khullar V, Uccelia S, Bertelli E, Ghezzi $F$ et al. Prospective study to assess risk factors for pelvic floor dysfunction after delivery. Acta Obstet Gynecol. 2008;87:313-8.

9. Thom DH, Rortveit G. Prevalence of postpartum urinary incontinence: a systematic review. Acta Obstet Gynecol. 2010;89:1511-22.

10. Solans-Domènech $M$, Sánchez $E$, Espuña-Pons $M$. Urinary and anal incontinence during pregnancy and postpartum. Obstet Gynecol. 2010;115(3):618-28.

11. MacArthur C, Glazener CMA, Wilson PD, Lancashire RJ, Herbison GP, Grant AM. Persistent urinary incontinence and delivery mode history: a six-year longitudinal study. BJOG. 2006;113:218-24.

12. Raza-Khan F, Graziano S, Kenton K, Shott S, Brubaker L. Peripartum urinary incontinence in a racially diverse obstetrical population. Int Urogynecol J. $2006 ; 17: 525-30$.
13. Wesnes SL, Hunskaar S, Bo K, Rortveit G. The effect of urinary incontinence status during pregnancy and delivery mode on incontinence postpartum. A cohort sudy. BJOG. 2009;116:700-7.

14. Lima JLDA, Lopes MHBM. Qualidade de vida em mulheres com incontinência urinária no puerpério. Rev Estima. 2011;9(2):12-21.

15. Higa R, Lopes MHBM, Turato ER. Psychocultural meanings of urinary incontinence in women: a review. Rev. Latino-Am. Enfermagem. 2008;16(4):779-86.

16. The World Health Organization Quality of Life Assessment (WHOQOL): position paper from the World Health Organization. Soc Sci Med. 1995;41(10):1403-9. 17. Seidl EMF, Zannon CMLC. Qualidade de vida e saúde: aspectos conceituais e metodológicos. Cad Saúde Pública. 2004;20(2):580-8.

18. Tamanini JTN, Dambros M, D ' ancona CAL, Palma PCR, Netto Jr NR. Validação para o português do "International Consultation on Incontinence Questionnaire-Short Form" (ICIQ-SF). Rev Saúde Pública. 2004;38(3):438-44.

19. Tamanini JTN, D'ancona CAL, Botega NJ, Netto Jr NR. Validação do "King's Health Questionnaire" para o português em mulheres com incontinência urinária. Rev Saúde Pública. 2003;37(2):203-11.

20. Ciconelli RM, Ferraz MB, Santos W, Meinão I, Quaresma MR. Tradução para a língua portuguesa e validação do questionário genérico de avaliação da qualidade de vida SF-36 (Brasil SF-36). Rev Bras Reumatol. 1999;39(3):143-50.

21. Diez-Itza I, Arrue M, Ibañez L, Murgiondo A, Paedes J, Sarasqueta C. Factors involved in stress urinary incontinence 1 year after first delivery. Int Urogynecol J. $2010 ; 21: 439-45$.

22. Coyne KS, Zhou Z, Thompson C, Versi E. The impact on health-related quality of life of stress, urge and mixed incontinence. BJU Int. 2003;92(7):731-5. 